\title{
Respiratory symptoms and airflow limitation in asphalt workers
}

\author{
B G Randem, B Ulvestad, I Burstyn, J Kongerud
}

Occup Environ Med 2004;61:367-369. doi: 10.1136/oem.2002.006114

Background: Asphalt workers are exposed to bitumen fume and vapour, and to exhaust from engines and passing traffic. Aims: To assess the occurrence of respiratory symptoms and signs of airflow limitations in a group of asphalt workers. Methods: All 64 asphalt workers and a reference group of 195 outdoor construction workers from the same company participated in a cross-sectional study. Spirometric tests and a questionnaire on respiratory symptoms and smoking habits were administered. Respiratory symptoms and lung function were adjusted for age and smoking.

Results: The $\mathrm{FEV}_{1} / \mathrm{FVC} \%$ ratio was significantly lower in the asphalt workers than in the referents. Symptoms of eye irritation, chest tightness, shortness of breath on exertion, chest wheezing, physician diagnosed asthma, and chronic obstructive pulmonary disease (COPD) were all significantly more prevalent among the asphalt workers.

Conclusion: In asphalt workers there is an increased risk of respiratory symptoms, lung function decline, and COPD compared to other construction workers.

r Norway, 4.5 million tons of asphalt are put down every year, exposing about 2000 asphalt workers to bitumen fumes and vapour. The fume and vapour consist of long chain hydrocarbons with very small concentrations of polycyclic aromatic hydrocarbons ( $\mathrm{PAH})$. In addition, the asphalt workers are exposed through inhalation to exhaust from engines and passing traffic.

Enhanced mortality from respiratory diseases, and enhanced prevalence of respiratory symptoms, has been reported in asphalt workers. In 1991, Hansen ${ }^{2}$ reported an SMR of 207 (95\% CI 95 to 393) from bronchitis, asthma, and emphysema in mastic asphalt workers. In a cross-sectional study, by Norseth et al, complaints of a sore throat or cough were more prevalent among the asphalt workers than among the road maintenance workers. ${ }^{3}$ Gamble et al ${ }^{4}$ reported a mean symptom score of $5.4 \%$ for cough among the asphalt workers in his study of asphalt fumes and acute effects on lung function. No association was found between lung function and measured levels of bitumen fumes across a work shift.

A large study of mortality involving 29820 European asphalt workers, completed in 2001, found that relative to construction workers, asphalt workers had an RR of 1.36 (95\% CI 1.06 to 1.74 ) of dying from a non-malignant respiratory disease. ${ }^{5}$

The question whether asphalt workers are at risk of developing work related obstructive lung disease is not clear. Obstructive pulmonary disease seems to be increasing in all age groups in the industrialised societies. ${ }^{6}$ Obstructive diseases can be divided into bronchial asthma and chronic obstructive pulmonary disease (COPD). The principal aim of the study was to assess the occurrence of respiratory symptoms and obstructive pulmonary disease in active asphalt workers compared to other outdoor construction workers.

\section{METHODS}

\section{Subjects}

All the asphalt employees (64 male workers) of one company located close to Oslo were studied. As a reference group 195 male outdoor construction workers belonging to the same company were included in the study. Data were collected in 1999. The study was approved by the National Data Inspectorate and the Regional Medical Board of Ethics.

\section{Exposure}

Asphalt in European nomenclature consists of $4-20 \%$ of bitumen mixed with crushed stone. In road paving the bitumen content is usually $4-5 \%$, whereas mastic asphalt contains about $8-13 \%$ of bitumen. The type of bitumen and the size of the gravel vary with the properties requested from the road surface. Filler and/or fibres may also be added in order to modify the properties of the asphalt, and aliphatic amines are used to improve binding between the bitumen and the stone material.

Depending on the type of asphalt paving, temperatures vary from $70^{\circ} \mathrm{C}$ (soft asphalt) to $220^{\circ} \mathrm{C}$ (mastic asphalt); paving temperatures around $140-150^{\circ} \mathrm{C}$ are common. Asphalt is produced by heating and drying the gravel and mixing the hot bitumen with it. The asphalt is transported to the paving site by trucks and emptied onto the front of the paving machine. The asphalt passes underneath the machine and is spread to the desired width and thickness by the screed. A screedman or foreman controls asphalt discharge through the screed and the rakers fix the edges of the asphalt on the road manually. Subsequently, a roller compresses the asphalt.

In 1992, asphalt workers of the studied company participated in an exposure monitoring study. Results are presented elsewhere. ${ }^{7}$ Full-shift personal breathing zone concentrations of a variety of PAHs, organic vapour, and bitumen fume were measured. In addition, $\mathrm{CO}$ and $\mathrm{NO}_{2}$ concentrations in the air were determined in the vicinity of asphalt paving equipment and for $\mathrm{CO}$ in personal breathing zones.

The exposure of the comparison group is described elsewhere. ${ }^{8}$ Outdoor construction workers are exposed to dust and oil mist, but at low levels (less than one third of the Norwegian occupational exposure levels).

\section{Assessment of respiratory health effects Questionnaire}

A self administered questionnaire applied in earlier Norwegian investigations and validated in 1989, ${ }^{9}$ was used to assess the presence of lower airways symptoms, allergy, physician diagnosed asthma, and smoking habits. Subjects were classified as never, former, and current smokers. In 


\section{Main messages}

- Asphalt workers reported significantly more respiratory symptoms than the reference group of outdoor construction workers.

- The $F E V_{1} / F V C \%$ ratio was significantly lower in the asphalt workers than in the referents.

- Asphalt workers had increased prevalences of chronic obstructive pulmonary disease and physician diagnosed asthma compared to the referents.

current and former smokers the quantitative effect of smoking was measured in pack-years.

\section{Spirometry}

Spirometric measurements were performed in the sitting position with a bellow spirometer, (Vitalograph S with PFT2 PLUS printer, Buckingham, UK), operated by the same trained technician. The measurements were performed in accordance with the guidelines recommended by the American Thoracic Society (1987). Recorded variables are forced vital capacity (FVC), forced expiratory volume in one second $\left(\mathrm{FEV}_{1}\right)$, and $\left(\mathrm{FEV}_{1} / \mathrm{FVC}\right) \times 100 \%$.

\section{Diagnostic criteria}

Subjects with a ratio of FEVI/FVC\% of less than 0.7 combined with history of chronic cough, phlegm when coughing, breathlessness, and/or wheezing were diagnosed as having chronic obstructive pulmonary disease (COPD). This was in accordance with diagnostic criteria previously applied in Norwegian population surveys. ${ }^{10}$ Asthma was coded positive in subjects reporting physician-diagnosed asthma.

\section{Data analysis}

The relation between respiratory symptoms and the covariates occupational group, smoking, and age was investigated by means of logistic regression. The covariate years employed in the same job was not included in the model due to high correlation $(>8)$ with the covariate age. Allergy and former smoking were controlled for, but did not have any influence on the models. The COPD and asthma data were analysed in the same way as were respiratory symptoms.

Statistical analyses were carried out using SPSS (version 10.0) statistical software package.

\section{RESULTS}

The asphalt workers were on average younger (37 $v 40$ years) and had worked fewer years ( $11 v 16$ years) in the present job than the reference workers. The prevalence of current smoking was similar in the two groups (53\% in both groups), as was pack-years of smoking ( $9 v 10$ years).

\section{Policy implications}

- The observation of exposure related pulmonary adverse effects in asphalt workers calls for better technological solutions for exposure prevention.

The asphalt workers reported a higher prevalence of respiratory symptoms compared to the outdoor construction workers (table 1). Asphalt workers had an eight times higher prevalence of physician diagnosed asthma relative to the outdoor construction workers, and a higher prevalence of COPD (table 1).

The ratio of $\mathrm{FEV}_{1} / \mathrm{FVC}$ was significantly decreased in the asphalt workers compared to the outdoor construction workers (78.1 (SD 7.2) $v 80.0$ (SD 7.0), $\mathrm{p}=0.01)$. There appeared to be no statistically significant differences in FVC and $\mathrm{FEV}_{1}$ between asphalt workers and controls, although asphalt workers tended to have lower lung function parameters.

\section{DISCUSSION}

Our findings agree with earlier studies which suggested that asphalt work is associated with acute irritant and respiratory symptoms. ${ }^{3}$ The asphalt workers in the present study had a significantly higher prevalence of physician diagnosed asthma than the outdoor construction workers. They also had a significantly higher prevalence of COPD than the outdoor construction workers, even though they were on average younger than the construction workers and had worked fewer years in the industry. Asphalt, but not outdoor construction workers, had increased prevalences of COPD compared to the general population. ${ }^{6}$ This supports the suggestion from mortality studies ${ }^{2}$ that asphalt work may be a contributing factor to development of obstructive lung diseases.

Smoking is an important factor for developing COPD, but differences in smoking habits cannot explain the difference in COPD in the present study, since the two worker groups had the same prevalence of smoking, and smoking was controlled for in the analysis.

To avoid a healthy worker selection bias, we chose a reference group that was comparable to the study group with respect to education, socioeconomic status, and selection for employment. Therefore, we believe that the observed differences in respiratory symptoms and airflow limitation between the asphalt workers and the outdoor construction workers may reflect differences in occupational exposure. A source of bias may be preferential recall of respiratory symptoms by the asphalt workers, since asphalt workers in this company have been subject to two earlier investigations (in 1987 and 1992) of occupational health or hygiene. ${ }^{37}$

Table 1 Number of workers (percentages) with respiratory symptoms, COPD, and asthma in asphalt workers and outdoor construction workers

\begin{tabular}{lrcrl}
\hline Symptom & Asphalt & Outdoor construction & OR* $^{*}$ & $95 \% \mathrm{Cl} \dagger$ \\
\hline Eye irritation & $14(21.9)$ & $18(9.2)$ & 2.8 & $(1.2$ to 5.9$)$ \\
Chest tightness & $14(21.9)$ & $18(9.2)$ & 2.8 & $(1.3$ to 5.9$)$ \\
Shortness of breath climbing stairs & $7(10.9)$ & $6(3.1)$ & 4.1 & $(1.3$ to 13.0$)$ \\
Chest wheezing & $25(39.1)$ & $40(20.5)$ & 2.6 & $(1.4$ to 4.9$)$ \\
Asthma diagnosed & $9(14.1)$ & $4(2.1)$ & 7.9 & $(2.3$ to 26.8$)$ \\
COPD & $12(18.8)$ & $15(7.7)$ & 2.8 & $(1.2$ to 6.5) \\
\hline
\end{tabular}

*OR (odds ratio) adjusted for smoking and age.

†95\% confidence limits of the odds ratio. 
However, a preferential recall would only result in overestimating symptoms and would not affect lung function tests. The cross-sectional design of the study may have lead to an underestimation of the effects of exposure because sensitive employees might have left the occupation. The workforce studied in cross-sectional surveys could be regarded as the trade's "survivors".

We did not have full occupational and exposure histories for the studied subjects. Therefore, they may have been exposed to chemical agents outside of asphalt paving or outdoor construction. This may bias estimates of the odds ratios and the differences in lung function in any direction. Furthermore, some of the asphalt workers may have been employed in outdoor construction at some time in the past and vice versa. This would introduce non-differential exposure misclassification that can be expected to attenuate observed odds ratios and differences in lung function.

The exposure levels and production conditions are typical of those observed in Norwegian and European asphalt industry in the late 1980s and early 1990s. ${ }^{137}$ Working conditions changed little through the 1990s. Particle bound PAHs, such as those occurring in bitumen fume and diesel exhaust, may contribute to oxidative stress and exert proinflammatory and tissue damaging effects that can contribute to respiratory morbidity. ${ }^{2}$

The present study supports the theory that work related exposures enhance the risk of respiratory symptoms, asthma, and COPD in asphalt workers.

\section{Authors' affiliations}

B G Randem, Centre for Occupational and Environmental Medicine, Rikshospitalet University Hospital, 0027 Oslo, Norway B Ulvestad, Cancer Registry of Norway, Montebello, 0310 Oslo, Norway
I Burstyn, University of Alberta, Edmonton, Canada J Kongerud, The Department of Pulmonary Medicine, Rikshospitalet University Hospital, 0027 Oslo, Norway

The project received financial support from the Working Environment Fund of the Confederation of Norwegian Business and Industry

Correspondence to: Dr B Randem, Centre for Occupational and Environmental Medicine, Rikshospitalet University Hospital, 0027 Oslo, Norway; britt-ra@online.no

Accepted 16 May 2003

\section{REFERENCES}

1 Burstyn I, Kromhout H, Boffetta P. A literature review of levels and determinants of exposure to potential carcinogens and other agents in the road construction industry. AlHA J 2000;61:715-26.

2 Hansen ES. Mortality of mastic asphalt workers. Scand J Work Environ Health $1991 ; 17: 20-4$.

3 Norseth T, Waage J, Dale I. Acute effects and exposure to organic compounds in road maintenance workers exposed to asphalt. Am J Ind Med 1991;20:737-44.

4 Gamble JF, Nicolich MJ, Barone NJ, et al. Exposure-response of asphalt fumes with changes in pulmonary function and symptoms. Scand J Work Environ Health 1999;25:186-206.

5 Boffetta P, Burstyn I, Partanen T, et al. IARC epidemiological study of cancer mortality among European Asphalt workers. Final report. Lyon, France: International Agency for Research on Cancer, 2001.

6 Bakke PS, Baste V, Hanoa R, et al. Prevalence of obstructive lung disease in a general population: relation to occupational title and exposure to some airborne agents. Thorax 1991;46:863-70.

7 Burstyn I, Randem B, Lien JE, et al. Bitumen, polycyclic aromatic hydrocarbons and vehicle exhaust: exposure levels and controls among Norwegian asphalt workers. Ann Occup Hyg 2002;46:79-87.

8 Ulvestad B, Bakke B, Melbostad E, et al. Increased risk of obstructive pulmonary disease in tunnel workers. Thorax 2000;55:277-82.

9 Burstyn I, Kromhout H, Kauppinen T, et al. Statistical modeling of determinants of historical exposure to bitumen and polycyclic aromatic hydrocarbons among paving workers. Ann Occup Hyg 2000;44:43-56.

10 Kongerud J, Vale JR, Aalen OO. Questionnaire reliability and validity for aluminium potroom workers. Scand J Work Environ Health 1989;15:364-70. 